\title{
GEDIFO: A Cross-Organizational Approach to Learning in Communities of Practice
}

\author{
http://dx.doi.org/10.3991/ijac.v7i2.3613 \\ Christina Merl $^{1}$ and Ulrich Schönbauer ${ }^{2}$ \\ 1 TalkShop.cc, Vienna, Austria \\ 2 Vienna Chamber of Labor
}

\begin{abstract}
This case study focuses on the situation of works councils who in today's globalized economy are challenged to represent the interests of employees on the one hand and to act as co-managers on the other. GEDIFO, a unique pilot initiative by the Vienna Chamber of Labor and the educational body of the Austrian Trade Union, seeks to empower and support works councils by promoting crossorganizational learning and peer coaching in communities of practice (CoP).
\end{abstract}

Index Terms-Community of Practice, CrossOrganizational Learning, Peer Exchange, Peer Coaching, Double-Loop Learning, Facilitation.

\section{INTRODUCTION}

In today's globalized economy, organizations face international competition, the need for technology-driven innovation, inefficiencies due to bureaucracy, severe costcutting, and frequently economic and social pressure as well as a deterioration in working conditions as a result thereof. Works councils are challenged to represent the interests of employees and at the same time to act as comanagers. In order to meet these challenges, they need to acquire negotiation and communication skills, social skills, ICT skills as well as legal knowledge and domain skills. GEDIFO (short for "Gesellschaftspolitisches Diskussionsforum" or socio-political discussion forum) is a unique pilot initiative by the Vienna Chamber of Labor (AK Wien) and the educational body of the Austrian Trade Union (VOEGB) that promotes crossorganizational learning for works councils of corporate and public sector organizations. GEDIFO's mission is to identify new trends and challenges on the labor market and to support works councils in acquiring the skills they need for developing and implementing timely and adequate measures aimed at promoting fair and sustainable working conditions for employees.

Currently, GEDIFO's focus is on six core areas (domains): workplace health promotion; continuing training of educationally disadvantaged employees; temporary agency work; corporate social responsibility; political campaigning; and age diversity in the workplace. These domains have been identified and defined by GEDIFO members (works councils) on the basis of their professional needs. GEDIFO membership is voluntary and free of charge. Domain skills, mutual engagement and readiness to take action in the organizational context are prerequisite for participation in GEDIFO. Facilitated meetings take place at regular intervals and are closely monitored by sponsors.

\section{A. History of learning within GEDIFO}

GEDIFO was founded 12 years ago under the label of "literature club" by Uli Schönbauer, a sociologist and systemic coach who is employed with the Vienna Chamber of Labor. Back then, works councils, members of the trade union, and external experts with an interest in sociopolitical topics were regularly invited to reflect ongoing trends and developments in society.

Over the years, and especially since the community of practice (CoP) model was introduced in 2011, GEDIFO has developed into a face-to-face platform where crossorganizational "out-of-the-box" thinking and learning has not only been "allowed" but fostered. Despite GEDIFO's non-hierarchical approach, the initiative is still quite strongly influenced by a traditional trade unionist mindset - such as strict hierarchical budgeting guidelines and a rather traditional attitude towards learning, training, and problem-solving. Against this background, "out-of-thebox" thinking indicates that works councils are encouraged to think and act beyond organizational, political, and hierarchical boundaries as well as to reflect their existing values and beliefs while trying out new ways of problemsolving to overcome the challenges they face in their organizations.

\section{B. Paradigm shift}

With the advent of the new technologies and the rise of the network society, organizations and works councils started to need more sustainable and self-organized learning processes. Accordingly, GEDIFO members have been exploring a variety of innovative learning approaches and participative techniques for effective and democratic decision-making, including the sociocracy model (see Buck and Villines, 2007) and the method of "organizing" as a strategy for political campaigning (see Shirky, 2009). Three years ago, GEDIFO introduced the community of practice (CoP) model as defined by Etienne Wenger and Jean Lave (1991), aimed at providing more sustainable learning within GEDIFO and at encouraging crossorganizational and cross-party peer coaching and learning. What differentiates this new approach to learning from former learning formats (such as project-based learning groups) is that individual problem-solving approaches are being looked at from a systemic theory point of view (see Königswieser \& Exner, 1998) and supported by systemicconstructivist coaching methods (see Fischer et al, 2013). In other words, works councils are encouraged and empowered to reflect their existing values and beliefs, to try out new ways of problem-solving in their organizational context, and to share and reflect their learning with peers. 
As far as the authors of this case study know, GEDIFO is currently the only such cross-organizational, crosshierarchical, cross-party initiative in Austria that promotes peer coaching and peer learning among works councils and trade union members in a CoP setting.

\section{LEARNING IN COPS}

\section{A. Introducing a new approach to learning}

In January 2011, GEDIFO introduced the concept of CoP as defined by Etienne Wenger (1998). "Communities of practice are groups of people who share a concern or a passion for something they do and learn how to do it better as they interact regularly."

A CoP consists of three components - domain, community, practice (ibid). Domain stands for shared interest in a topic and means that membership implies both mutual engagement and domain skills. Community refers to the fact that members of a CoP - practitioners - interact regularly to pursue their shared goals, thus building a social relationship and learning together. This aspect differentiates a CoP from a loose community of interest and a project-based working group or task force. Practice implies the shared repertoire of resources that are produced by members as a result of their learning, including experiences, stories, tools, and ways of addressing recurring problems in their work field.

In the case of GEDIFO, establishing the six CoPs has taken a considerable amount of time and sustained interaction as well as tailored coaching by facilitators and external experts. The facilitation team consists of GEDIFO founder and host Uli Schönbauer and of Christina Merl, a social learning expert and CoP consultant. Initiating and nourishing these CoPs despite the hierarchical structures and traditional mindset of sponsoring organizations as well as making CoP members aware that hands-on solutions must come from them on the basis of their expertise and practical experience have been the major challenges for the facilitation team. Actually, facilitators have put a considerable amount of time and effort to empower and encourage GEDIFO members to reflect their existing values and beliefs; to co-develop hands-on solutions to problems they face in daily work; to take action in their real-life organizational context; and to reflect their learning together with peers.

CoP meetings take place at regular intervals; the focus of these meetings is on developing practice-oriented steps and activities. It should be mentioned that GEDIFO host Uli Schönbauer has to report to sponsors at regular intervals and to justify why it makes sense to continue sponsoring the CoP approach.

\section{B. Double-loop learning}

Frequently, works councils may face resistance as a result of deeply rooted political traditions, strict hierarchical structures, and last but not least as a result of neoliberal tendencies that increasingly dominate their work context. They have to represent the interests of employees and at the same time to act as co-managers. GEDIFO's approach to learning differs from traditional learning formats in that it provides systemic coaching interventions that make works councils realize that they may need to change their underlying values and beliefs as well as to reframe their goals in order to achieve satisfactory results in their organizational context.

For example, in the field of workplace health promotion, two works councils in Vienna and Lower Austria experience major troubles in their hospitals. The hospitals need to cut costs, which leads to an increase in burnout cases and a decrease in staff performance. The works councils face major resistance at the political level and feel helpless. Against this background, GEDIFO facilitators organized a "systemic constellation" meeting. This coaching intervention helped the two affected works councils to understand specific processes and political positions better and also to reframe their own thinking and approach. In addition, they got valuable feedback and advice from peers who work in different organizations. As a result, the two works councils felt empowered and started to build alliances and to develop an action plan that should help them improve the situation in their hospitals.

This process of reconsidering existing assumptions and re-assessing fixed values and goals may be compared to double-loop learning as defined by Argyris \& Schön (1996). There, individuals and/or organizations are able to modify or even reject their goals in the light of practical experience (see Fig. 1).

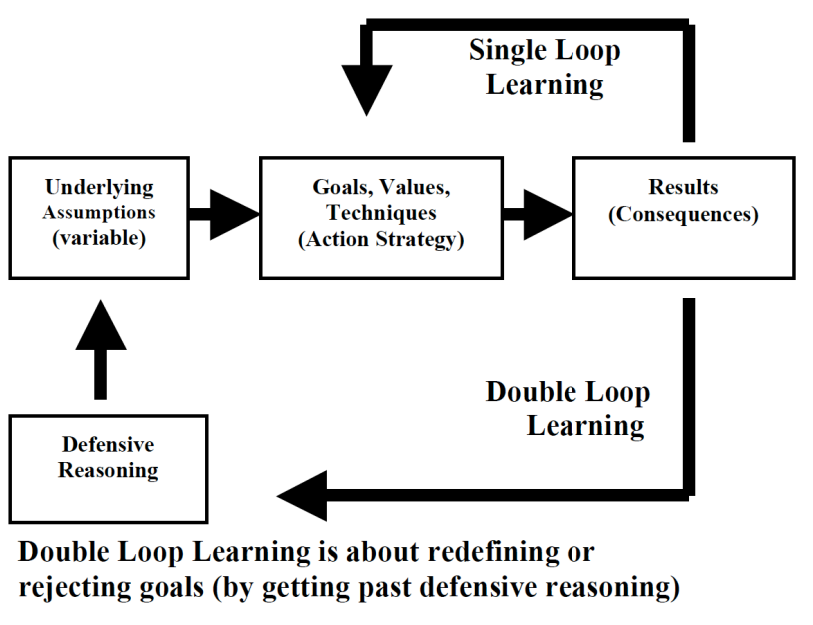

Figure 1. double loop learning

GEDIFO provides a space where works councils can reflect their practical experience with peers. They get feedback from peers and experts and thus can further develop their practice, re-define or even reject their current goals and try out new ways of problem-solving.

While single-loop learning (see Argyris \& Schön, 1978 ) involves trying out different strategies and modifying actions to achieve different outcomes, double-loop learning requires a deeper assessment of existing values, assumptions and policies that led to the actions in the first place, and modifying those. In the context of GEDIFO, works councils are encouraged to assess their situation, values, and strategies at a deeper level. Together, they find out how they need to reframe their values and objectives in order to obtain satisfactory results. Double loop learning has proven very necessary and valuable for GEDIFO members. After all, they have confirmed that their regular CoP meetings do not only provide one of their main sources of knowledge and know-how but also a valuable space for reflection about their practice and learning. A member of GEDIFO, a works council of a semi-privatized 
Vienna-based social care organization, describes her learning experience as follows:

"GEDIFO has opened up a new world to us. A world where we can exchange our thoughts and experiences, learn with and from each other and pursue common goals across political and organizational boundaries. What is more, we do not only discuss things on a theoretical level but look behind the scenes and take action. We develop concrete solutions and strategies together and implement them in our work fields. GEDIFO provides a platform where we can discuss our practice and get feedback and advice from peers and experts. It therefore stands for knowledge transfer, awareness-building, networking, collaboration, and finally for taking action and implementing measures. This is what makes GEDIFO successful: Members learn from and with each other and benefit as a group as well as individually. "(Doris B.)

\section{The facilitation process}

The past three years have been characterized by cultivating and nurturing the six CoPs (workplace health promotion; continuing training of educationally disadvantaged employees; temporary agency work; corporate social responsibility; political campaigning; and more recently, age diversity in the workplace.)

The individual CoPs comprise between 7 and 20 members; facilitated meetings take place at regular intervals; the role of facilitators has been to initiate the CoPs as well as to encourage members to define and develop the three elements - domain, community, practice - in parallel. For this, various methods and coaching interventions have been used, including expert round tables, world café (Brown and Isaacs, 2005), the fishbowl format (KeckMcNulty, 2004), and especially the systemicconstructivist methodology of coaching (see Fischer et al, 2013) that has been transformed into a specific peer coaching design to serve GEDIFO purposes.

Artefacts have been produced by CoP members, including mission statements, a little GEDIFO booklet, GEDIFO badges, video statements, etc. Furthermore, topic-related events and workshops have been organized by the individual CoPs at regular intervals with the aim to push their subject and to raise awareness among works councils.

The facilitation process cannot be put into a clear-cut recipe as the dynamics of the individual CoPs are very different and unpredictable. For example, facilitators thought of closing down the CoP for temporary agency work and discussed that option with core members two years ago. All of a sudden, the interest in the topic grew, and the number of members increased. The CoP started to flourish and meanwhile counts over 20 members. It is hard to predict the life span and dynamics of a CoP as it depends a lot on the overall social and political interest in the domain, on the motivation of members, their mutual engagement, commitment as well as time resources.

Facilitators have learned that they need to be very flexible and constantly adapt the facilitation process to the needs of CoP members. One major difficulty is to remain flexible within the strict hierarchical structures of the sponsoring organizations. One key to success may be the clear focus on concrete outcomes. Facilitators demand from CoP members that they are clear on which activities they want to take in their real life organizational context. This is how members stay focused and the CoPs are pre- vented from developing into a pure discussion club. Once works councils have become familiar with the CoP approach and once they have started to see the impact of their activities in real life, they have become more active and committed.

\section{Out-of-the-box thinking}

It has taken a major effort by facilitators to "channel" the expertise and creativity of CoP members and to encourage them to think "out of the box". As most GEDIFO members come from very hierarchical organizational and traditional political backgrounds, they were used to hierarchical settings and traditional learning groups with fixed objectives, such as project teams, learning groups, instructional trainings, and traditional seminars. It took facilitators quite some time to make members aware that they themselves are the experts who can change things for the better in their organizational context and that hands-on solutions must come from them. This learning process has demanded a lot of flexibility, creativity, and vision on the part of facilitators. Their role has been to empower members; to push them towards re-assessing their existing values and beliefs; and also to provide the setting where they can reflect together with peers on the effectiveness of their individual activities. As a matter of fact, "out-of-thebox thinking" is an important aspect of the peer-coaching approach as applied in the GEDIFO context. Members are invited to dig deeper, assess their existing assumptions, reframe their thinking and co-develop new ways of problem-solving.

\section{E. Definition of roles}

A major challenge in the community building process has been the definition of roles within the individual CoPs. Each CoP consists of a number of core members and also peripheral members who contribute on an irregular basis. In the beginning, facilitators have taken the leading role. In some CoPs, individual members started to take an active role out of their own initiative. For example, two members have taken a leading role in the work health promotion $\mathrm{CoP}$, meaning they have started to co-organize meetings and agendas. The same happened in the temporary agency work CoP. Also, several task forces have formed within the various CoPs that work on solutions for specific problems that are relevant to all members. In the meantime, experts from the sponsoring organizations have started to join CoP meetings as they can benefit from practitioners' experiences and points of view for their daily work; further, their role is to support CoP members with regard to legal and political questions.

It can be said that a flourishing CoP needs a visionary leader - someone who has a clear vision, takes the initiative and is able to motivate the others and to share their experiences and develop hands-on solutions.

\section{F. Meta CoP: cross-CoP learning and networking}

Three or four times per year, core members of the individual CoPs meet to exchange important insights and to make strategic decisions that are relevant for all CoPs. This cross-CoP meeting format is called "Meta CoP" and gives CoP members the opportunity to connect and exchange valuable insights, information, and practical experience. More recently, a growing number of practitioners have demanded increased cross-CoP learning and networking even if they have limited time resources. Their 
wish for more cross-CoP exchange seems to imply that they benefit from cross-topical, cross-organizational, cross-party peer exchange and learning.

\section{G. Technology-driven learning}

Originally, GEDIFO sponsors planned to install online CoPs when the new approach was taken up in 2011. The learning should take place within a Moodle supported setting where online discussion spaces had been created for members of the individual CoPs. At least, some fruitful discussions took place in the online environment. However, the enormous need for online facilitation posed a budgetary challenge. What's more, members were clearly in favor of face-to-face interaction for several reasons. For example, some core members simply lack the necessary technological and social media skills. They say it is because of their age (some of them are over 50 and do not need social media skills in their job). Many of them seem to lack the time and motivation to engage in online discussion and learning out of office hours. Also, members are clearly reluctant to discuss delicate legal issues in an online environment. They prefer face-to-face settings and personal conversation for this. In order to not lose the dynamics of the overall process, facilitators agreed to replace the online platform by face-to-face meetings and to move in the direction of online discussions at a later point. Social media skills trainings were provided without big success. As GEDIFO is a rather small initiative with limited budget, the initial wish to install online discussion forums has been postponed.

At least, an official GEDIFO blog (www.gedifo.at) and a Facebook site as well as a Twitter account have been installed. Facilitators and sponsoring organizations would clearly like to see more learning and activities to take place online as they think the GEDIFO spirit could be well transmitted online and reach a wider target group. For this purpose, an online media team was recently set up. This team consists of a member of each $\mathrm{CoP}$ and will strive to find a more systematic and motivating approach towards spreading the GEDIFO spirit online and also to encourage other members to join in online discussions and learning. However, members are still reluctant to discuss their topics in a social media setting as they fear a lack of data security and of giving confidential information that might be used against them at some point. At the moment, it seems that works councils prefer to discuss delicate matters and strategies in a face-to-face setting.

\section{H. The added value of professional facilitation}

Last but not least, it should be pointed out that professional facilitation of CoP meetings is pre-requisite to successful meeting outcomes. Without professional facilitation, members tend to discuss their challenges without considering concrete solutions and taking concrete steps. The role of facilitators has therefore been to identify current trends, define strategies, and smoothly guide $\mathrm{CoP}$ members in "the right direction" in order to get good meeting outcomes. Adequate coaching interventions have been used, such as peer coaching, expert round tables, world cafés, portrait painting, creating artefacts, etc. The overall goal of facilitators is to nourish the self-organizing spirit among $\mathrm{CoP}$ members and to inspire and empower individual members to take more and more of a leading role.

\section{LEARNING WITH CONCRETE PRACTICAL OUTPUT}

Learning within GEDIFO has to be result-oriented. Sponsors want to see concrete outcome of CoP meetings and they want to use results to improve their own programs as well as to promote their (political) interests. It should be pointed out that sponsors expect fast results despite severe budget restrictions. Experience has shown that CoPs need time to develop and that they need to be nourished continuously. This takes a lot of time, patience, vision, flexibility and especially communication and empathy from the facilitators. CoP members have very limited time resources and need to be encouraged and empowered by facilitators quite a lot. It can be said that CoPs do not just sprout up organically but that they have to be created and nourished via "artificial insemination". Once members are on board, however, they feel the energy and dynamics that inspires them to contribute and share their know-how and co-develop hands-on solutions to improve the situation in their organizations.

Even if GEDIFO is seen as a laboratory of trial and error, it is quite strongly influenced by a traditional trade unionist mindset, meaning, among other things, that strict (budgetary and decision-making) guidelines have to be followed. It takes a lot of effort to convince sponsors that relevant knowledge nowadays resides in networks and that most relevant workplace learning today is experiential, unplanned, social, and informal. As the dynamics of the individual CoPs is hard to predict, facilitators are challenged to guide learning processes within GEDIFO with utmost flexibility. At the same time, they have to operate within strict hierarchical structures as set by sponsoring organizations.

GEDIFO seeks to embrace and foster social networking and learning across organizational, hierarchical, and political boundaries with the aim to provide sustainable support for practitioners who struggle with the increasing complexity, unpredictability, and uncertainty in their organizational contexts.

After all, some knowledge transfer from the individual CoPs to the sponsoring organizations has been achieved. Experts of the sponsoring organizations started to participate in the CoP meetings as they can gain inspiration and interesting contributions for their own work while feeding CoP members with important legal and other know-how. For example, a press conference was organized by sponsoring organizations where the results of the CoP on temporary agency work were presented to a large number of Austrian newspapers and other media. Further, some important cross-organizational alliances have been built in the field of health promotion. Last but not least, experts from the sponsoring organizations can get valuable insights into the corporate world through the CoPs. It seems that cross-organizational, informal, and social learning in CoPs is a key to works councils achievements in today's business climate.

\section{REFERENCES}

[1] M. Castells, "The Rise of the Network Society (The Information Age: Economy, Society and Culture), vol. 1, 1996.

[2] E. Wenger, J. Lave, "Situated Learning: Legitimate Peripheral Participation”, September 1991, ISBN: 9780521423748

[3] E. Wenger, "Communities of Practice: Learning, Meaning, and Identity", Cambridge University Press, 1998 http://dx.doi.org/10.1017/CBO9780511803932 


\section{CASE STUDY}

GEDIFO: A CROSS-ORGANIZATIONAL APPROACH TO LEARNING IN COMMUNITIES OF PRACTICE

[4] Argyris, C. and Schön, D., "Organizational learning II: Theory, method and practice", Reading, Mass: Addison Wesley, 1996.

[5] Argyris, C.; Schön, D., 1978, "Organizational Learning: A theory of action perspective." Reading MA: Addison-Wesley. ISBN 0201-00174-8.

[6] Buck, John; Villines, Sharon (2007). We the People: Consenting to a Deeper Democracy, A Guide to Sociocratic Principles and Methods. Sociocracy.info Press. ISBN 978-0-9792827-0-6.

[7] Shirky, Clay (2009) Here Comes Everybody: The Power of Organizing without Organizations. Penguin Books; Reprint edition (February 24, 2009). ISBN-10: 0143114948

[8] Brown, Juanita; Isaacs, David (2005) The World Café Shaping Our Futures Through Conversations That Matter; Paperback ISBN 9781576752586

[9] Cynthia L Keck-McNulty (2004) Group leadership training: what is learned using a fishbowl method ISBN 9781576752586

[10] Königswieser, Roswita \& Exner, Alexander (1998) Systemische
Intervention - Architektur und Designs für Berater und Veränderungsmanager, Klett-Kotta, ISBN-10: 3608919384.

[11] Fischer, Hans Rudi, von Schlippe, Arist, Borst, Ulrike (2013) Durch die Wüste - Visionen auf dem Kamel, Familiendynamik 2/2013, ISBN-10: 3129711112.

\section{AUTHORS}

Christina Merl is the owner of TalkShop.cc and works as a $\mathrm{CoP}$ consultant, language and social learning professional from Vienna (e-mail cmerl@talkshop.cc)

Ulrich Schönbauer is a sociologist and systemic coach and is employed by the Vienna Chamber of Labor (e-mail: ulrich.schoenbauer@akwien.at)

Submitted on 01 June 2014. Published as re-submitted by the authors 08 June 2014. 